\title{
Biofilm Control: Conventional and Alternative Approaches
}

\author{
H.-C. Flemming (『) and H. Ridgway
}

\begin{abstract}
Biofouling" is referred to as the unwanted deposition and growth of biofilms. This phenomenon can occur in an extremely wide range of opportunities ranging from colonization of medical devices, during production of ultrapure drinking and process water, and fouling of ship hulls, pipelines and reservoirs. Although biofouling occurs in such different areas, it has a common cause, which is the biofilm. Biofilms are the most successful form of life on earth and tolerate high concentrations of biocidal substances. Conventional anti-fouling approaches usually rely on the efficacy of biocides, aiming for inhibition of biofilm growth. It is important to keep in mind that killing of biofilm organisms usually does not solve biofouling problems as mostly the biomass is the problem and must be removed. Therefore, cleaning is at least equally important. However, for a sustainable antifouling strategy, an advanced approach is suggested, which includes the analysis of the fouling situation, a selection of suitable components of the "anti-fouling menu" and an effective and representative monitoring of biofilm development. One important part of this menu is nutrient limitation, which could be implemented on a much broader scale than is practiced today. Other items on the menu include methods to monitor unwanted biofilm development and assessment of the efficacy of anti-fouling measures. Also, natural anti-fouling strategies are worth exploring and learning from - and nature never relies on only one defence line but on integrated approaches.
\end{abstract}

\section{What is Biofouling?}

The term "biofouling" is referred to as the undesired development of microbial layers on surfaces. This operationally defined term has been adapted from heat exchanger technology where "fouling" is defined generally as the undesired deposition of material on surfaces, including:

\footnotetext{
H.-C. Flemming

IWW Centre for Water, Moritzstrasse 26, 45476, Muelheim Germany

e-mail: hanscurtflemming@compuserve.com
} 
- Scaling, mineral fouling: deposition of inorganic material precipitating on a surface

- Organic fouling: deposition of organic substances (e.g. oil, proteins, humic substances)

- Particle fouling: deposition of, e.g., silica, clay, humic substances and other particles

- Biofouling: adhesion of microorganisms to surfaces and biofilm development

In the first three kinds of fouling, the increase of a fouling layer arises from the transport and abiotic accumulation on the surface of material from the water phase. What is deposited on the surface originates quantitatively from the water. In these cases, fouling can be controlled by eliminating the foulants from the liquid phase. However, this is different in the case of biofouling: microorganisms are "pseudo-particles", which can multiply. Even if $99.99 \%$ of all bacteria are eliminated by pre-treatment (e.g. microfiltration or biocide application), a few surviving cells will enter the system, adhere to surfaces, and multiply at the expense of biodegradable substances dissolved in the bulk aqueous phase. Thus, microorganisms convert dissolved organic material into biomass locally, through metabolic transformations. These metabolic processes, i.e. biodegradation and surface growth, form the basis of biofilm reactors (e.g. membrane bioreactors) that have been introduced in the past decade. Biofouling can be considered as a "biofilm reactor in the wrong place and time". Substances suitable as nutrients, which would not act as foulants per se, will support fouling indirectly. Although most current anti-fouling measures target the microorganisms directly (e.g. chlorine disinfection of a potable water system), the role of nutrients as a potential source of biomass is frequently overlooked.

Moreover, biocides tend not to decrease the nutrient level that ultimately supports the biofilm. On the contrary, nutrients released into solution by the oxidative breakdown of normally recalcitrant organics can support rapid post-biocide (LeChevallier 1991). As it is virtually impossible to keep a common industrial system completely sterile, microorganisms on surfaces will always be present, "waiting" for traces of nutrients. Thus, all biodegradable substances must be considered as potential biomass.

Usually, the different kinds of fouling mentioned above occur together. The proportion of biofouling can be considerable. An example is the development of dental plaque, i.e. mineral depositions on teeth which is favoured by biofilms. In algal biofilms, precipitation of calcium carbonate is increased, mainly due to the rise in $\mathrm{pH}$ resulting from photosynthesis (Callow et al. 1988). However, other mechanisms may also play a role such as changing of the water activity by EPS molecules. Generally, biofouling has to be considered as a biofilm problem. In order to understand the effects and dynamics of biofouling and to design appropriate countermeasures, it is important to understand the natural processes of biofilm formation and development.

From a microbiological point of view, there is no "typical" fouling organism. If excessive biomass or non-specific contamination of the water phase is the problem, it will be the most abundant organism in a given site that will be the main fouling organism. If metabolic products cause the problem, such as low-chain fatty acids, hydrogen sulphide or inorganic acids, the organisms producing these substances will cause the fouling. Again, "fouling" is an operational expression, which is defined by the specific physicochemical and biological characteristics of a system. 
Nearly all microorganisms are capable of forming biofilms as this is a universal way of microbial life. Practical observations revealed that particularly slimy strains of environmental bacteria may prevail in water system biofilms (Wingender and Flemming, personal observation). Usually, the composition of fouling biofilms is dominated by the autochthonic flora, which can differ profoundly with different fouling sites and conditions, including those systems whose microbial flora has been perturbed by the application of biocides.

Biofouling in the sense of the given definition can occur in extremely diverse situations ranging from space stations (Koenig et al. 1997) to profane explanations for religious miracles like that of Bolsena, which is attributed to the growth of Serratia marcescens on sacramental bread and polenta. Communion cups have been identified as potential infection risks due to biofilms on the chalices (Fiedler et al. 1998). In medicine, implant devices such as catheters are prone to biofouling. Dental waterlines can be seriously contaminated by pathogens (Barbeau et al. 1998). In general, it is acknowledged now that biofilms are a common cause for infections (Costerton et al. 1999). Cases, causes and countermeasures have been reviewed (e.g., Flemming 2002) and more are presented in this book.

In technical systems, a less considered problem is the fact that biofilms can provide a habitat for pathogenic microorganisms. Biofouling, therefore, may be not only a technical problem but can also imply the exposure of working personnel to such pathogens released from biofilms. The contamination risk can occur from skin contact and from inhalation of aerosols. Klebsiella, Mycobacterium, Legionella, Escherichia coli and coliform organisms have been found in water system biofilms (LeChevallier et al. 1990) from where they can detach and will be found in the water phase. In the presence of corrosion products, pathogens seem to be particularly protected. This is the conclusion of the study of Emde et al. (1992), which found a much higher variety of species in corrosion product deposits, called "tubercles", compared to the free water phase, even after extended periods of chlorination. The fate of viruses in biofilms is still in question. Reasoner (1988) reports very occasional incidence of pathogens in drinking water biofilms. This is confirmed by a large study on drinking water distribution system biofilms carried out currently in Germany. First results indicate that some pathogens seem to be even eliminated by the autochthonic biofilms (Wingender and Flemming, personal observation). In distribution systems, due to the surface to volume ratio, more than $95 \%$ of the entire biomass is located at the walls and less than 5\% in the water phase (Flemming 1998). These biofilms contribute considerably to the overall purification process because they degrade diluted organic matter. There is no correlation between the cell concentration in the water and in the biofilm, although most of the cells found in the water phase originate from biofilms. However, ongoing large field research reveals that biofilms developing on certified materials seem not to represent a threat to drinking water and in general do not harbour potentially pathogenic organisms (Kilb et al. 2003). The situation is different if materials are involved that support microbial growth. An example is shown in Fig. 1a: massive biofilm formation on synthetic elastomers in drinking water pipelines. Figure $1 \mathrm{~b}$ shows a scanning electron micrograph of the same biofilm. The size of the cells indicates very good growth conditions, in contrast to starving microcolonies, which are usually found on 


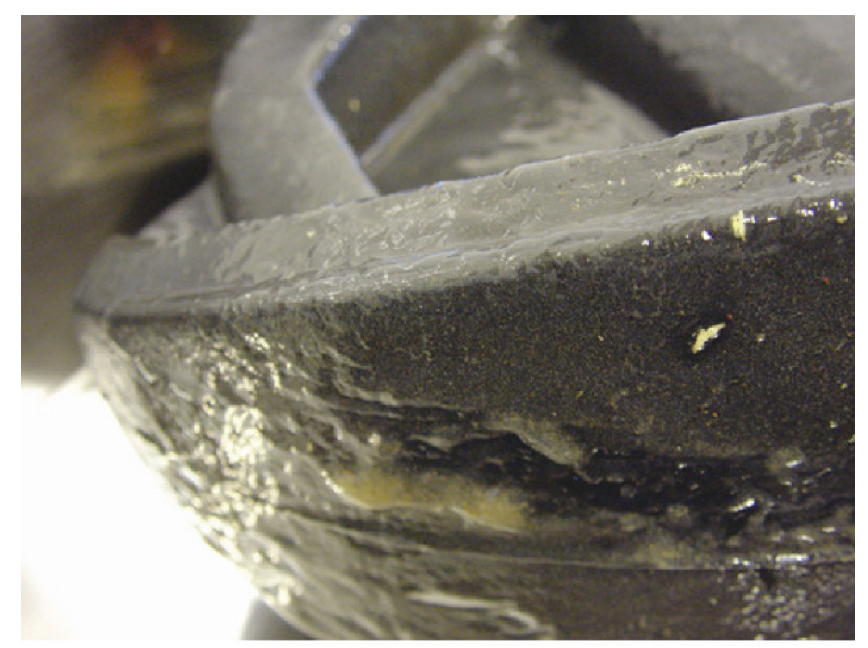

a

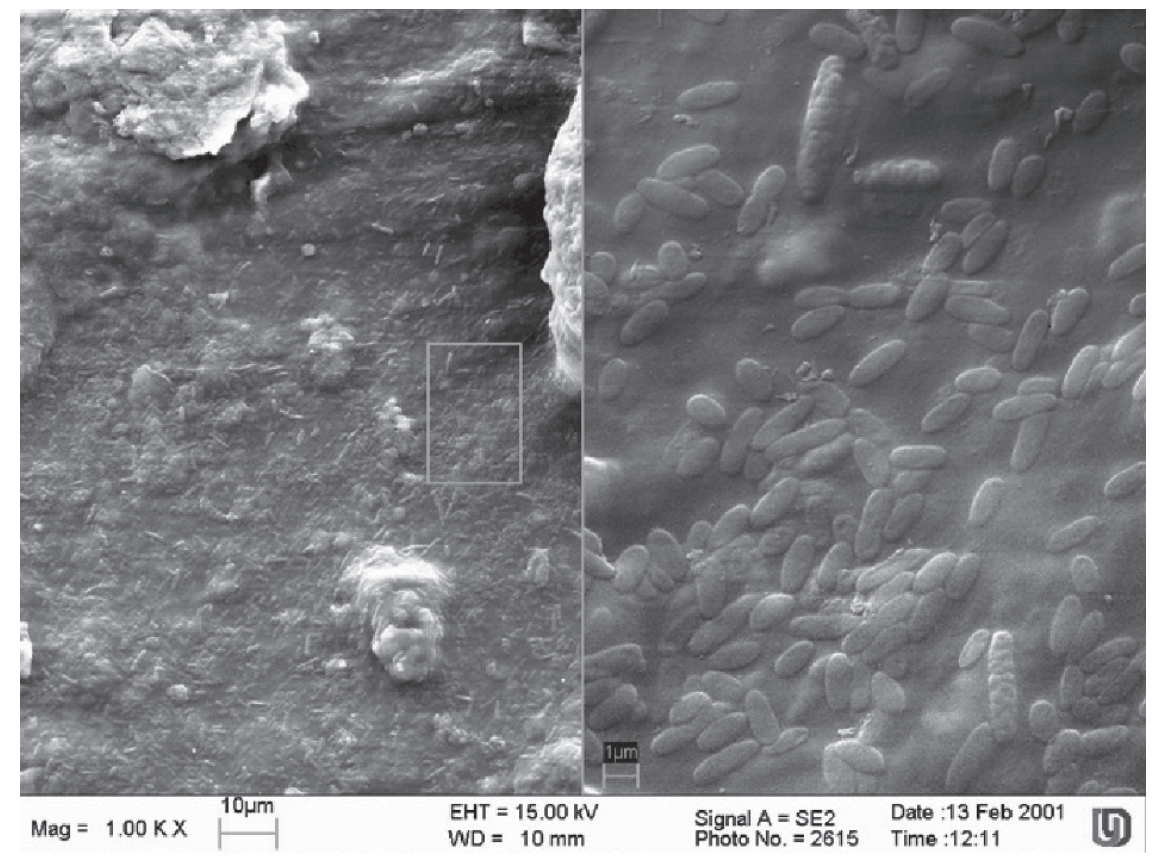

b

Fig. 1 a Massive biofilm development on an elastomer coating of a valve in a drinking water system (Kilb et al. 2003). b Scanning electron micrograph of a section of a. Right: magnification of a section of the micrograph on the left (courtesy of G. Schaule) 
materials that do not leach nutrients. This biofilm harboured coliform bacteria, which were detected in downstream drinking water samples.

\section{Countermeasures}

In biofouling cases, it is reasonable to follow a three step protocol:

1. Identification of the cause and localization of the problem

2. Sanitation (cleaning is as important as killing the microorganisms)

3. Prevention

This has been described in detail earlier (Flemming 2). Usually, if a problem arises in a process, the diagnosis "biofouling" will be attributed if other causes do not explain the phenomena. In order to design the most effective countermeasures, it is important, to verify this diagnosis. This has to be performed by sampling of the surfaces, which requires a set of more sophisticated techniques (Schaule et al. 2000) than sampling of the water phase, although the latter is unfortunately performed exclusively in most cases. The most common countermeasure against unwanted microbial growth is the use of biocides (Flemming and Schaule 1996). This line of thinking expands a medical paradigm to technical systems: the colonization by bacteria is considered as a kind of "illness" that has to be cured by some means of disinfectant, antibiotic or other biocide. However, it is well known that biofilm organisms display a much higher tolerance to biocidal agents than their freely suspended counterparts (LeChevallier et al. 1991). Various mechanisms are discussed that may protect biofilm organisms (McBain 2001). The most plausible explanation is based on a diffusion-limitation of the biocide by the EPS matrix. However, recent measurements have revealed that this cannot be the case. Small molecules experience practically no diffusion limitation in a biofilm matrix. Only if they react with EPS components (as is the case with oxidizing biocides such as chlorine or ozone) is consumption of the biocide and, thus, a concentration gradient observed, caused by reaction with EPS components (Schulte et al. 2005). Tolerance against hydrogen peroxide is frequently accompanied by an enhanced catalase activity. In general, enhanced biocide tolerance must be taken into account in anti-fouling applications (Morton et al. 1998).

\subsection{An Integrated Anti-fouling Strategy}

A more complex and hopefully more effective approach to combating biofilms may be stimulated by an increasingly restrictive legislation towards biocides, particularly in the EU, although the relevant literature cannot be exhaustively reviewed here (for further details see Flemming and Greenhalgh 2008). It is important not to rely only on one "wonder weapon" but to analyse all fouling factors and to develop an integrated 
approach, based on detailed knowledge of biofilm development. The basic idea is "to live with biofilms", an approach that may well inspire creativity in new directions (Flemming 2002).

Biofouling is an operational definition, referring to that amount of biofilm development that interferes with technical, aesthetic or economical requirements. Research on reverse osmosis (RO) membrane biofouling revealed that biofilms commence development within the first moments of operation, thereby contributing to the demise of the separation process without any knowledge or forewarning that such processes are at work (Griebe and Flemming 1998). Only after observing a certain reduced membrane permeability is the "level of interference" passed and biofouling is said to have occurred. This motif can be transferred to other water systems; they practically all carry biofilms, but not all of them suffer from biofouling. Figure 2 shows schematically the development of biofilms in a system.

What are the options for keeping biofilm development in a system below the individual level of interference? Basically, the extent of biofilm growth is grossly ruled by the availability of nutrients and the shear forces. Thus, nutrients must be considered as potential biomass. This is an important issue as, usually, biocidal approaches do not take this aspect into account and do not limit nutrients; to the contrary, some biocides increase the nutrient content by oxidizing recalcitrant organics and rendering them more bioavailable (LeChevallier 1991). Nutrient limitation has been demonstrated successfully as a countermeasure to biofouling (Griebe and Flemming 1998). By using biological sand filters prior to RO membranes it was possible to suppress the extent of biofilm growth below the threshold of interference, although the membrane was not completely free of a biofilm (Table 1).

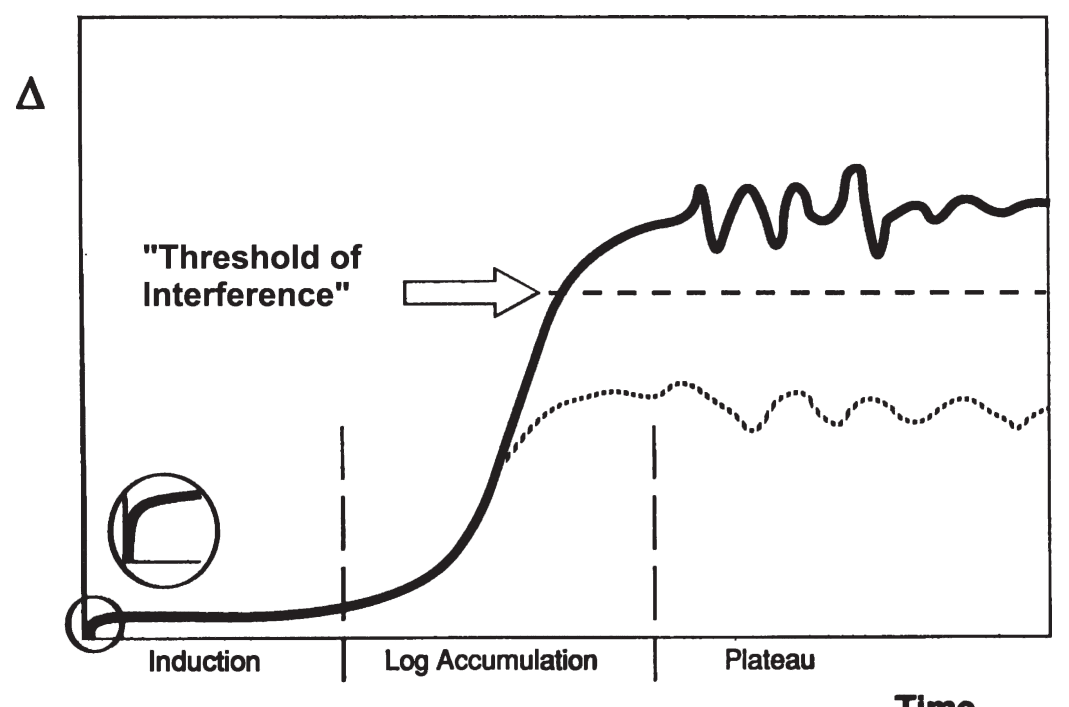

Fig. 2 Schematic of biofilm development. Dotted line arbitrary threshold of interference (after Flemming et al. 1994) 
Table 1 Deposit data from membranes before and after biological filter

\begin{tabular}{llll}
\hline Parameter & Unit & Before filter & After filter \\
\hline Cell number & $\# / \mathrm{cm}^{2}$ & $1.0 \times 108$ & $5.5 \times 106$ \\
CFU & $\# / \mathrm{cm}^{2}$ & $1.0 \times 107$ & $1.2 \times 106$ \\
Protein & $\mu \mathrm{g} \mathrm{cm}^{-2}$ & 78 & 4 \\
Carbohydrates & $\mu \mathrm{g} \mathrm{cm}^{-2}$ & 26 & 3 \\
Uronic acids & $\mu \mathrm{g} \mathrm{cm}^{-2}$ & 11 & 2 \\
Humic substances & $\mu \mathrm{g} \mathrm{cm}^{-2}$ & 41 & 12 \\
Biofilm thickness & $\mu \mathrm{m}$ & 27 & 3 \\
Flux decline & $\%$ & 35 & $<2$ \\
\hline
\end{tabular}

Obviously, this approach cannot be applied in all cases. However, there still remain plenty of opportunities where it provides a suitable and realistic alternative to adding biocides for prevention of biofouling. This approach would certainly reduce the burden of wastewater with environmentally problematic substances and certainly deserves more attention.

\subsubsection{Surface Design and Primary Adhesion}

Clearly, rough surfaces are more prone to microbial colonization than smooth surfaces. This has been confirmed with stainless steel surfaces (Faille et al. 2000). However, even on the smoothest surface, bacteria can attach. This is the result of unsuccessful approaches to prevent biofouling in heat exchangers by electropolishing. In order to understand what happens when a bacterial cell comes into contact with a surface, it is helpful to take the entire situation in account. As shown in Fig. 3 for the example of a Gram-negative organism, cells are surrounded by extracellular material. Also, surfaces immersed in water become within seconds covered with a so-called conditioning film consisting of macromolecules such as humic substances, polysaccharides and proteins, which are present in trace amounts in water. This has long since been known (Loeb and Neihof 1975) but not taken into account. The cells do not need to be viable for adhesion, the already present EPS are sufficient for adhesion (Flemming and Schaule 1988)

Many approaches have been followed in order to prevent microbial adhesion. Until now, only three of them have been successful:

1. Tributyl tin anti-fouling compounds. However, these are so toxic to marine organisms that they have been widely banned from use.

2. Natural anti-fouling compounds. Such compounds have been isolated mainly from marine plants that are not colonized by bacteria (Terlezzi 2000). Steinberg et al. (1997) have isolated signalling molecules from an Australian seaweed exhibiting anti-colonizing activity. More marine anti-fouling products have been investigated by Armstrong et al. (2000) and Tirrschof (2000). The problem with all these compounds is that most of them are only scarcely available, they are difficult to apply on a constant basis on a surface, and they will select for organisms 


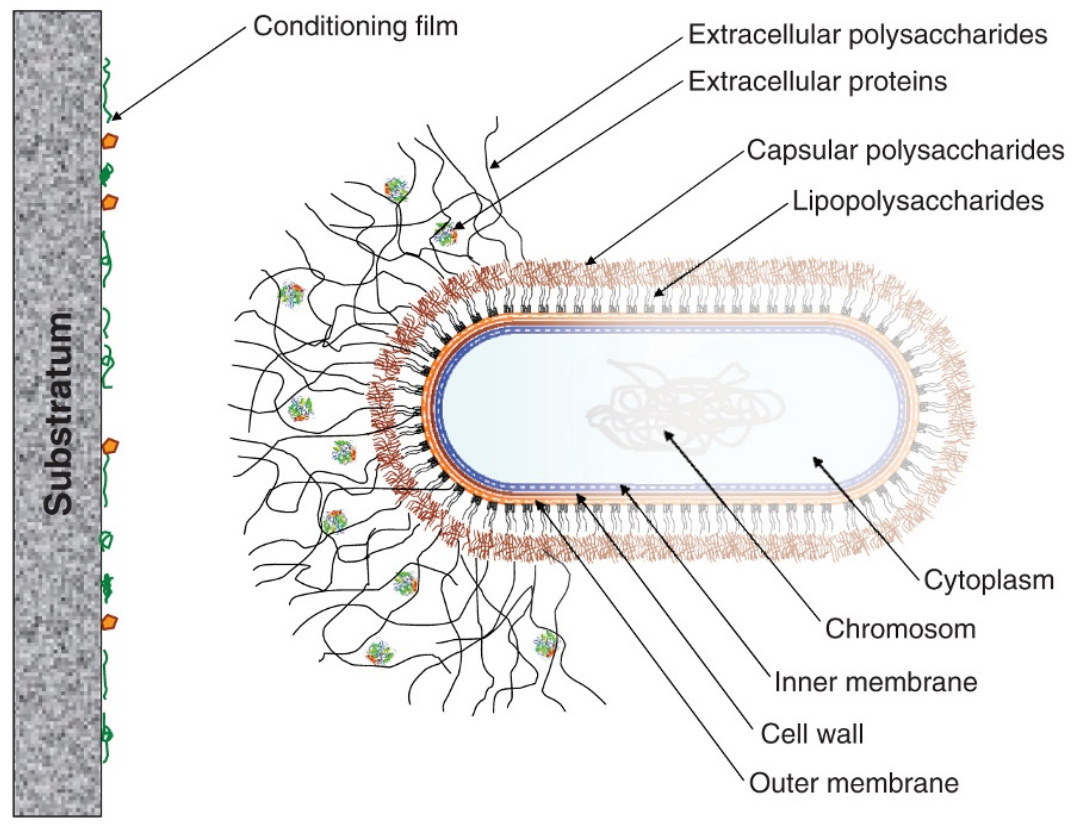

Fig. 3 Situation of a Gram-negative bacterium encountering a non-biological surface in water (after Flemming 2003)

that can overcome the effect. Apart from that, they will have to undergo the EU biocide guideline procedure, which is assessed to cost about 5-10 million € per substance. Further aspects of natural anti-fouling compounds are discussed in other chapters in this volume.

3. Surfaces with lotus effect (Neinhuis and Barthlott 1997). This effect relates to the "purity of the sacred lotus" (which is shared by less sacred cabbage leaves as well) based on the particular structure of the wax layers on the leaf surface. A highly hydrophobic pattern of needles will prevent water from moistening the surface due to the physicochemical interactions of three phases: solid, liquid and gaseous. By nature, this effect is not possible with immersed surfaces. Also, as soon as surface-active substances cover the hydrophobic pattern, surface tension decreases and water is no longer repelled. Thus, the lotus effect can be taken advantage of only on solid-air interfaces and only if no surfactants are used. However, other approaches, such as the influence of surface texture microstructure, have been pursued (Bers and Wahl 2004). They found that the surface structure of Ophiura texturata significantly repelled primary adhesion. However, the translation of this effect into technical application has not yet succeeded.

As a consequence, we will have to live with the fact that most surfaces can and will be colonized by microorganisms, which will cause fouling given the right conditions. Nevertheless, surfaces susceptible to biofouling may be "re-engineered" to discourage fouling. For example, Louie et al. (2006) recently demonstrated that thin-film composite 
RO membranes could be coated with a polyether-polyamide copolymer (PEBAX 1657), which penetrated deeply into the membrane surface resulting in a smoother hydrophilic surface. Compared to uncoated controls, the coated RO membranes displayed a significant reduction in fouling by an oil/surfactant/water emulsion in trials lasting more than 100 days.

A more novel approach to designing low-fouling surfaces that is still in its early stages of development involves the application of molecular simulations to observe and measure in silico the dynamics of surface fouling by macromolecular substances. An example of this approach is illustrated in Fig. 4 in which a hydrated oligomer of bacterial alginate is shown undergoing rapid adsorption to the "surface" of an aromatic cross-linked polyamide RO membrane. The system potential energy is shown to decline substantially in this molecular dynamics simulation (inset), suggesting this type of adsorption interaction is energetically favourable. The aim of such modelling exercises is to introduce chemical modifications into the (polyamide) surface that will inhibit or impede such rapid macromolecular fouling.

The alginate oligomer is positioned initially $(\mathrm{t}=0)$ above the membrane surface fragment (left vertical panel). The $\mathrm{t}=0$ positions are viewed from three spatial perspectives: side view (top), oblique view (middle), and top-down view (lower).
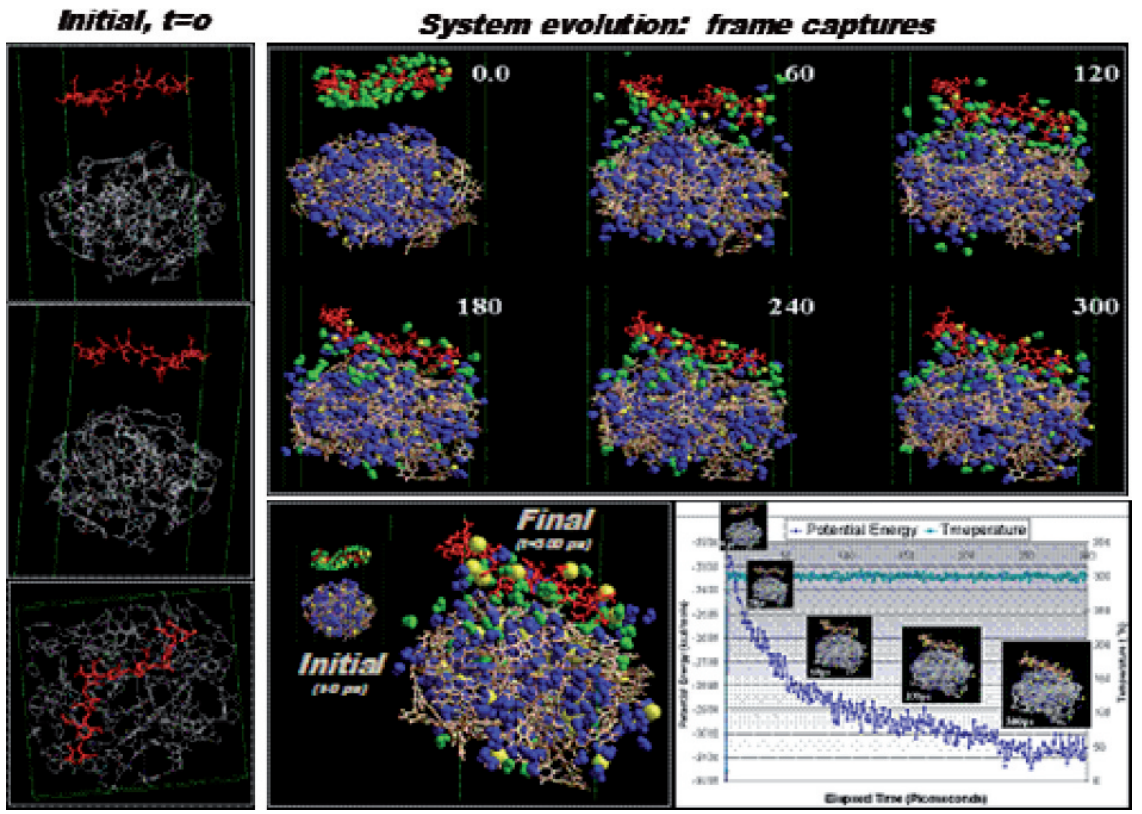

Fig. 4 Molecular dynamics (MD) simulation of alginate adsorption to a polyamide (PA) reverse osmosis membrane "surface" (H. Ridgway, AquaMem Scientific Consultants and Stanford University, unpublished data). The MD simulation shows rapid adsorption of a hydrated oligomer of bacterial alginate (red) to the PA surface (brown). Water molecules associated with the alginate are green. Membrane-associated water is blue. For more details see text. Frame capture times are given in picoseconds 
Water and sodium counter ions have been hidden in the $\mathrm{t}=0$ images to better observe the alginate and membrane atoms. The right-hand upper panel indicates that alginate adsorption occurred relatively rapidly over a period of about $300 \mathrm{ps}$. As indicated by a decline in the system potential energy (inset graph), alginate adsorption was thermodynamically favourable. Alginate and membrane bonds are represented as sticks; water atoms are given as blue or green depending on whether they were initially associated with membrane or alginate, respectively.

\subsubsection{Biofilm Management}

In actual practice in a variety of systems, biofilm development can be successfully controlled through the application of a combination of cost-effective strategies,

Such a multi-factorial approach can be described as "biofilm management" and focuses on the limitation of factors that support biofilm growth above the "level of interference" (see Fig. 2). A successful example is the use of sand filters in order to remove biodegradable matter from cooling water in order to protect membrane units from biofouling (Griebe and Flemming 1998). Nutrient limitation is meanwhile an accepted approach to minimize fouling. A thorough fouling factor analysis is necessary, which must include in the first place the assessment of the nutrient situation. It has been explained earlier that nutrients have to be considered as potential biomass. High shear forces will limit excessive biofilm development, although they will not prevent it. Under high shear stress, there will be a selection for organisms that produce mechanically stable biofilms. Limiting the access of microorganisms will also be helpful; however, it must be taken into account that cells are particles that can multiply.

Cleaning is an important issue in biofilm management. For cleaning, cohesion of the biofilm and adhesion to surfaces have to be overcome, which are both aspects of the mechanical stability of biofilms. Koerstgens et al. (2001) have developed a film rheometer that allows for the quantification of biofilm stability with the apparent elasticity module $\varepsilon$ as a relevant parameter. This research revealed that the EPS matrix is kept together by weak physicochemical interactions, which result in a fluctuating network of adhesion points. In compression experiments it was shown that until a yield point $\sigma$ is reached, biofilms behave as gels with constant partner groups responsible for the adhesion. After exceeding $\sigma$, the gel breaks down, the partners of the adhesion points change and the biofilm behaves as a highly viscous fluid. This is why biofilms are slippery. In a model system with Pseudomonas aeruginosa, it was shown that $\mathrm{Ca}^{2+}$ ions increase the stability of the network by bridging alginate molecules, which are the main component of $P$. aeruginosa EPS. $\mathrm{Mg}^{2+} \mathrm{did}$ not show such an effect, but $\mathrm{Fe}^{2+}, \mathrm{Fe}^{3+}$ and $\mathrm{Cu}^{2+}$ did. Most commercial cleaners and biodispersants, however, proved ineffective in this testing system. An effective weakening of the EPS matrix can be achieved by enzymes (Johansen et al. 1997). However, this is not a fast effect and, in practice, it has proven transient and ineffective in many cases (e.g. Klahre et al. 1998). This is not surprising as EPS, like other struc- 
tural biopolymers, are not readily biodegradable. Also, continuous use of enzymes will select for organisms producing EPS that are not susceptible to these enzymes.

An important aspect in cleaning is the use of surfaces to which biofilms do not attach strongly. Such materials have been developed and tested for anti-fouling on ship hulls and fishing nets, with silcones as a promising class of compound (Terlezzi et al. 2000; Estarlich et al. 2000; Holm et al. 2000). Anti-fouling polymer coatings were mentioned above (Louie et al. 2006). Modelling surface-foulant interactions (as described above) should help elucidate how anti-fouling coatings and antifouling surface treatments prevent primary macromolecular adsorption.

Electric fields have been used both for prevention of microbial adhesion and for inhibition of biofilm growth (Matsunaga et al. 1998, Kerr et al. 1999; Schaule et al., 2008). Practical observation, however, has shown that all kinds of electrodes immersed into water can be colonized and fouled by biofilms. Another approach to slow down biofouling processes and to facilitate cleaning is the use of coatings that can change their surface properties reversibly, induced by external stimuli such as light, temperature or $\mathrm{pH}$ value (Flemming, current research). Very interesting is the observation that surfaces with pulsed polarization show significantly lower biofilm growth over time (Schaule et al. 2008).

\subsubsection{Biofilm Monitoring}

It is of great importance to monitor biofilm development in order to optimize the time-course and effectiveness of countermeasures. This is not possible by sampling of the bulk water phase. Such samples give no information about the site, the extent and the composition of a biofilm and they generally underestimate by orders of magnitude the true microbial (surface) burden of a system. Although biofilms contaminate the water phase, they do so not on a constant basis but very irregularly. Biofilm cells may erode, but sloughing events may happen as well, leading to intermittent high cell numbers in the bulk water phase. Thus, biofilm monitoring must be performed using representative surfaces.

Conventional methods rely on sampling of defined surface areas or on exposure of test surfaces ("coupons") with subsequent analysis in the laboratory. A classical example is the "Robbins device" (Ruseska et al. 1982), which consists of plugs smoothly inserted into pipe walls, experiencing the same shear stress as the wall itself. After given periods of time, they are removed and analysed in the laboratory for all biofilm-relevant parameters. The disadvantage of such systems is the time-lag between analysis and result. Jacobs et al. (1996) described a simple spectrophotometric monitoring method using a nucleotide fluorescent stain (DAPI) and automatic measurement.

Other methods have been invented that report biofilm growth on-line, in real time and non-destructively. They all are based on physical methods. One example is the fibre optical device (FOS), which is based on a light fibre integrated in the test surface, measuring the scattered light of material deposited on the tip. The principle of the sensor is schematically depicted in Fig. 5a, a typical graph is shown in Fig. 5b (Tamachkiarow and Flemming 2003). Detection of autofluorescence of 


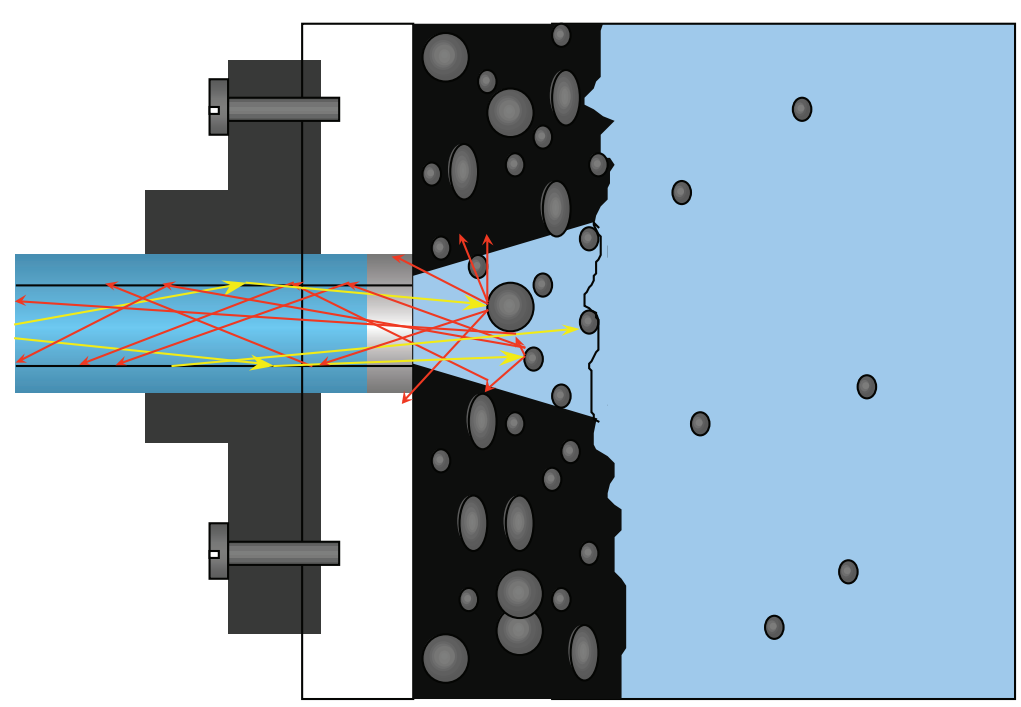

a

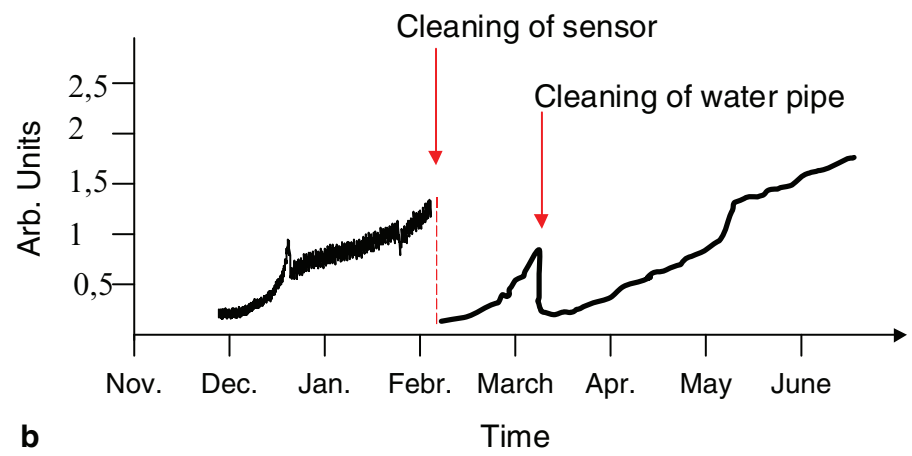

Fig. 5 a Schematic depiction of a fibre optical device (FOS). The tip of the fibre is integrated into the water-exposed surface. Light is coupled in by the sending fibre. Material deposited on the tip will scatter light, which is collected in the reading fibre. b Typical graph of intensity of backscattered light as provided by the FOS (after Tamachkiarow and Flemming 2003)

biomolecules by spectroscopy allows differentiation of biological material in the deposit from abiotic material.

Another method uses two turbidity measurement devices, one of which is constantly cleaned. The difference of the signals is proportional to the biomass developing on the non-cleaned window (Klahre et al. 2000). Nivens et al. (1995) have given an excellent overview on continuous non-destructive biofilm monitoring techniques, including FTIR spectroscopy, microscopic, electrochemical and piezoelectric techniques, which have also been systematically described by Flemming (2003). 


\section{Conclusions}

An "integrated anti-fouling strategy"will not aim to kill all organisms in a system but keep them below a threshold of interference. The strategy has to be based on:

1. Multi-factorial analysis of the fouling situation

2. Installation of early warning systems

3. Limiting nutrient availability where ever possible (raw water, materials, additives etc.)

4. Prioritizing cleaning over killing

5. Effective and representative monitoring of cleaning measures

Any step towards a better understanding of biofilm growth and properties will add to the "menu" and expand the possibilities for a flexible, effective and environmentally suitable response to biofouling.

\section{References}

Armstrong E, Boyd KG, Pisacane A, Peppiatt CJ, Burgess JG (2000) Marine microbial natural products in antifouling coatings. Biofouling 16:215-224

Barbeau J, Gauthier C, Payment P (1998) Biofilms, infectious agents, and dental unit waterlines: a review. Can J Microbiol 44:1019-1028

Bers AV, Wahl M (2004) The influence of natural surface microtopographies on fouling. Biofouling 20:43-51

Callow ME, Pitchers RA, Santos R (1988) Non-biocidal anti-fouling coatings. In: Houghton DR, Smith RN, Eggins HOW (eds) Biodeterioration, 7, Elsevier Applied Sciences, New York, pp. $43-48$

Costerton JW, Stewart PS, Greenberg EP (1999) Bacterial biofilms: a common cause of persistent infections. Science 284:1318-1322

Emde KME, Smith DW, Facey R (1992) Initial investigation of microbially influenced corrosion (MIC) in a low temperature water distribution system. Water Res 26:169-175

Estarlich FF, Lewey SA, Nevell TG, Thorpe AA, Tsibouklis J, Upton AC (2000) The surface properties of some silicone and fluorosilicone coating materials immersed in seawater. Biofouling 16:263-275

Faille C, Membre JM, Tissier JP, Bellon-Fontaine MN, Carpentier B, Laroche MA, Benezech T (2000) Influence of physicochemical properties on the hygienic status of stainless steel with various finishes. Biofouling 15:261-274

Fiedler K, Lindner M, Edel B, Wallbrecht F (1998) Infection from the communion cup: an underestimated risk? Zbl Hyg Umweltmed 201:167-188

Flemming HC, Greenhalgh M (2008) Concept and consequences of the EU biocide guideline. Springer Ser Biofilms. doi: 10.1007/7142_2008_12

Flemming HC, Schaule G (1996) Measures against biofouling. In: Heitz E, Sand W, Flemming H-C (eds.) Microbially influenced corrosion of materials - scientific and technological aspects. Springer, Heidelberg Berlin New York, pp. 121-139

Flemming HC, Tamachkiarowa A, Klahre J, Schmitt J (1998) Monitoring of fouling and biofouling in technical systems. Water Sci Technol 38:291-298

Flemming HC, Schaule G (1988) Biofouling on membranes - a microbiological approach. Desalination 70:95-119 
Flemming H-C, Schaule G, McDonogh R, Ridgway HF (1994) Mechanism and extent of membrane biofouling. In:Geesey GG, Lewandowski Z, Flemming H-C (eds.)Biofouling and biocorrosion in industrial water systems.Lewis, Chelsea, MI, pp. 63-89

Flemming HC (2002) Biofouling in water systems - cases, causes, countermeasures. Appl Environ Biotechnol 59:629-640

Flemming H-C (2003) Role and levels of real time monitoring for successful anti-fouling strategies. Water Sci Technol 47(5):1-8

Griebe T, Flemming HC (1998) Biocide-free antifouling strategy to protect RO membranes from biofouling. Desalination 118:153-156

Holm ER, Nedved BT, Phillips N, Deangelis KL, Hadfield MG Smith CM (2000) Temporal and spatial variation in the fouling of silicone coatings in Pearl Harbour, Hawaii. Biofouling 15:95-107

Jacobs L, De Bruyn EE, Cloete TE (1996) Spectrophotometric monitoring of biofouling. Water Sci Technol 34(5-6):533-540

Johansen C, Falholr P, Gram L (1997) Enzymatic removal and disinfection of bacterial biofilms. Appl Environ Microbiol 63:3724-3728

Kerr A, Hodgkiess T, Cowling MJ, Smith MJ, Beveridge CM (1999) Effect of galvanically induced surface potentials on marine fouling. Lett Appl Microbiol 29:56-60

Kilb B, Lange B, Schaule G, Wingender J, Flemming HC (2003) Contamination of drinking water by coliforms from biofilms grown on rubber-coated valves. Int J Hyg Environ Health 206(6):563-573

Klahre J, Flemming HC (2000) Monitoring of biofouling in papermill water systems. Water Res 34:3657-3665

Klahre J, Lustenberger M, Flemming HC (1998) Microbial problems in paper production. Part III: monitoring. Das Papier 52:590-596

Koenig DW (1997) Microbiology of the space shuttle water system. Water Sci Technol 35(11-12):59-64

Koerstgens V, Wingender J, Flemming HC, Borchard W (2001) Influence of calcium-ion concentration on the mechanical properties of a model biofilm of Pseudomonas aeruginosa. Water Sci Technol 43(6):49-57

LeChevallier MW (1990) Coliform regrowth in drinking water: a review. J Am Water Works Assoc 92 (11):74-86

LeChevallier MW (1991) Biocides and the current status of biofouling control in water systems. In: Flemming HC, Geesey GG (eds) Biofouling and biocorrosion in industrial water systems. Springer, Heidelberg Berlin New York, pp. 113-132

Loeb FI, Neihof RA (1975) Marine conditioning films. In: Baier RE (ed) Applied chemistry at protein interfaces. Am Chem Soc, Washington, pp. 319-335

Louie JS, Pinnau I, Ciobanu I, Ishida KP, Ng A, Reinhard M (2006): Effects of polyether-polyamide block copolymer coating on performance and fouling of reverse osmosis membranes. J Membr Sci 280:762-770

Matsunaga T, Nakayama T, Wake H, Takahashi M, Okochi M, Nakamura N (1998) Prevention of marine biofoling using a condictive paint electrode. Biotechnol Bioeng 59:374-378

McBain AJ (2001) Do biofilms present a nidus for the evolution of antibacterial resistance?. In: Gilbert P, Allison D, Brading M, Verran J, Walker J (eds.) Biofilm community interactions: chance or necessity? BioLine Press, Cardiff, pp. 341-351

Morton LHG, Greenway DLA, Gaylarde CC, Surman SB (1998) Consideration of some implications of the resistance of biofilms to biocides. Int Biodeterior Biodegradation 41:247-259

Neinhuis C, Barthlott W (1997) Characterization and distribution of water-repellent, self-cleaning plant surfaces. Ann Bot 79:667-677

Nivens DE, Palmer RJ, White DC (1995) Continuous nondestructive monitoring of microbial biofilms: a review of analytical techniques. J Ind Microbiol 15:263-276

Reasoner DJ (1988) Drinking water microbiology research in the United States: an overview of the past decade. Water Sci Technol 20:101-107 
Ruseska I, Robbins J, Lashen ES, Costerton JW (1982) Biocide testing against corrosion-causing oilfield bacteria helps control plugging. Oil Gas J 253-264

Schaule G, Griebe T, Flemming HC (2000) Steps of biofilm sampling and characterization in biofouling cases. In: Flemming HC, Griebe T, Szewzyk U (eds) Biofilms, investigative methods and applications. Technomics, Lancaster, PA, pp. 1-21

Schaule G, Rumpf A, Weidlich C, Mangold C, Flemming H-C (2008) Influence of polarization of electric conductive polymers on bacterial adhesion. Poster at IWA conference on biofilms, Wat Sci Techn, in press

Schulte S, Wingender J, Flemming H-C (2005) Efficacy of biocides against biofilms. In: Paulus W (ed.) Directory of microbicides for the protection of materials and processes. Kluwer, Doordrecht, pp. $90-120$

Steinberg PD, de Nys R, Kjelleberg S (1997) Chemical defenses of seaweeds against microbial colonization. Biodegradation 8:211-220

Tamachkiarow A, Flemming HC (2003) On-line monitoring of biofilm formation in a brewery water pipeline system with a fibre optical device (FOS). Water Sci Technol 47(5):19-24

Terlezzi A, Conte E, Zupo V, Mazzella L (2000) Biological succession on silicone fouling-release surfaces: long term exposure tests in the harbour of Ischia, Italy. Biofouling 15:327-342

Tirrschof D (2000) Natural product antifoulants: one perspective on the challenges related to coatings development. Biofouling 15:119-127 